\title{
The adherence and illness perception of patients diagnosed with asthma or chronic obstructive pulmonary disease treated with polytherapy using new generation Cyclohaler
}

\author{
Magdalena Olszanecka-Glinianowicz', Agnieszka Almgren-Rachtan² \\ ${ }^{1}$ Health Promotion and Obesity Management Unit, Department of Pathophysiology, Medical Faculty in Katowice, Medical University \\ of Silesia \\ Head of the Unit: Prof. Magdalena Olszanecka-Glinianowicz MD, PhD \\ ${ }^{2}$ Safety and Pharmacovigilance Department, Europharma Rachtan Ltd., Katowice, Poland
}

Postep Derm Alergol 2014; XXXI, 4: 235-246 DOI: $10.5114 /$ pdia.2014.45070

\begin{abstract}
Introduction: The factors influencing adherence of patients diagnosed with asthma and chronic obstructive pulmonary disease (COPD) include the complexity of the therapy, fear of side effects of drugs, method of taking the drug, dosage regimen, polypharmacy, adverse events, knowledge about the essence of the disease and its complications, illness perception and priorities in life, training on the use of the inhaler, the duration of treatment, social support, and drug availability.

Aim: To assess the adherence of patients diagnosed with asthma and COPD treated with polytherapy with fluticasone propionate and formoterol fumarate using the Fantasmino inhaler in relation to primary diagnosis and illness perception as well as patients' and doctors' opinion about this form of therapy.

Material and methods: A questionnaire survey covering adherence, illness perception and opinion about polytherapy using new generation Cyclohaler performed by pulmonologists, allergologists and general practitioners in 3,618 patients with asthma and 2,602 with COPD.

Results: On visit 1, a lower adherence rate was observed in COPD than in the asthma group (72.0\% vs. $61.5 \%$; $p<0.01)$. During the observation, the adherence rate increased significantly in the COPD group, only $(61.5 \%$ vs. $73.0 \% ; p<0.01)$. A negative correlation between total MMAS-8 and BIPQ scores was observed in both study groups $(R=-0.15 ; p<0.001$ and $R=-0.24 ; p<0.001$, respectively). During the observation, a percentage of patients who believed that the administration of the two drugs in a single inhaler considerably facilitates their use increased significantly in both study groups. In addition, an increased percentage of doctors believed that this therapeutic option facilitated education of patients and decreased the number of errors made by the patients.

Conclusions: The illness perception, younger age, disease duration and severity are predictors of adherence to treatment with fluticasone propionate and formoterol fumarate using the Fantasmino inhaler among patients with asthma and COPD. The positive opinion of patients and doctors about administration of fluticasone propionate and formoterol fumarate using the Fantasmino inhaler increased during observation.
\end{abstract}

Key words: asthma, chronic obstructive pulmonary disease, adherence, polytherapy, new generation Cyclohaler.

\section{Introduction}

Asthma and chronic obstructive pulmonary disease (COPD) are common diseases in the Polish population $[1,2]$. Both are progressive diseases and their exacerbations are a threat to life. The appropriate pharmacotherapy slows the progression of these diseases, reduces the number of exacerbations and improves quality of life [3, 4]. Currently the preferred form of pharmacotherapy in asthma and COPD are drugs administered directly into the bronchial tree in the form of inhaled formulations. The benefit of this form of therapy over oral or parenteral use of drugs include rapid onset of action, high concentrations at the target site, the possibility of using lower doses and minimizing side effects. Polytherapy involves inhaled glucocorticosteroids and long-acting $\beta_{2}$-agonist acting on both key links of asthma and COPD pathogenesis - bronchoconstriction and inflammation [3, 4]. However, the effectiveness of pharmacotherapy depends

Address for correspondence: Prof. Magdalena Olszanecka-Glinianowicz MD, PhD, Health Promotion and Obesity Management Unit, Department of Pathophysiology, 18 Medyków St, 40-752 Katowice, Poland, phone/fax: +48 3225 26 091, e-mail: magols@esculap.pl Received: 22.08.2014, accepted: 27.08.2014. 
primarily on patient cooperation including adherence that consists of two components: compliance and persistence. Factors influencing the inclusion of the patient in the treatment process include attitude towards the disease (disease negation, underestimation of disease, exaggerating, adequate attitude), image of disease, the importance of the disease to the patient, doctor-patient communication [5]. Numerous studies revealed adherence of about $60 \%$ of patients diagnosed with asthma and COPD $[6,7]$. The factors influencing adherence include the complexity of the therapy, fear of side effects of drugs, method of taking the drug, dosage regimen, polypharmacy, adverse events, knowledge about the essence of the disease and its complications, illness perception and priorities in life, training on the use of the inhaler, the duration of treatment, social support, and drug availability [8].

As mentioned above, asthma and COPD in most cases require polytherapy and the method of taking the drug is one of factors influencing adherence. Thus, possibility of administration of two formulations using one type of the inhaler may be the factor influencing adherence. It has been shown that the use of dry powder inhaler (DPIs) in the I generation inhaler (Cyclohaler and Diskhaler) is associated with a lower number of patients making mistakes during preparation and use of equipment for the same inhalation [9]. In addition, Pallen et al. [10] revealed that when using the Cyclohaler most of the maneuvers were performed correctly by $100 \%$ of patients. In 2006 , the U.S. patented a new generation Cyclohaler, which is available on the Polish market under the name Fantasmino. This inhaler makes it possible to use two formulations: fluticasone propionate and formoterol fumarate. There are no studies assessing adherence and illness perception in patients with asthma or COPD treated with polytherapy using the Fantasmino inhaler as well as opinion of patients and doctors about this form of therapy.

\section{Aim}

\section{Therefore, the aims of the study were:}

1. to assess the adherence in patients diagnosed with asthma and COPD treated with polytherapy with fluticasone propionate and formoterol fumarate using the Fantasmino inhaler in relation to primary diagnosis and illness perception.

2. to assess patients' and doctors' opinion about this form of therapy.

\section{Material and methods}

In this observational survey, 3,618 patients diagnosed with asthma (56.9\% of women) and 2,602 diagnosed with COPD (42.7\% of women) were interviewed nationwide by 311 pulmonologists, allergologists and general practitioners in 2013-2014. Polish doctors participating in the study were recruited by medical representatives, and each of them conducted questionnaire interviews with a group of 6220 consecutive patients visiting the clinic for asthma or COPD treated with fluticasone propionate and formoterol fumarate using the Fantasmino inhaler during two successive visits resulting from the needs of therapy.

The inclusion criteria were age $\geq 18$ years, diagnosis of asthma or COPD, current polytherapy with fluticasone propionate and formoterol fumarate using the Fantasmino inhaler at least 14 days prior to enrollment. The exclusion criteria included age below 18 years, inability to obtain the patient's answers to the questions included in the survey, patient's refusal. Characteristics of the surveyed population are summarized in Table 1.

The questionnaire consisted of several dichotomous and multiple choice questions.

The questionnaire on visit 1 consisted of four parts including demographic data (gender, age, place of residence, education and employment status), medical history (primary diagnosis, disease duration and severity, exacerbation of disease since the last visit, hospitalization due to exacerbation of primary disease since the last visit, the current treatment, duration of the therapy with fluticasone propionate and formoterol fumarate and duration of this therapy using the Fantasmino inhaler), the reasons for non-adherence. In the fourth part of the interview, comprising closed-ended questions, patients and doctors expressed their opinions on the use of the Fantasmino inhaler (facilitation adherence, facilitation of the patient education, reduction in the number of errors made during the inhalation, treatment effectiveness).

The questionnaire on visit 2 consisted of two parts concerning continuation of treatment with fluticasone propionate and formoterol fumarate, possible reasons for treatment discontinuation and the reasons for non-adherence. In the second part, similar questions as at visit 1 were asked to assess patients' and doctors' opinions.

In addition, on both visits, Morisky 8-item medication adherence questionnaire (MMAS-8) and Brief Illness Perception Questionnaire (BIPQ) Polish version were included in the study questionnaire. Each item of the BIPQ assessed one dimension of IP such as the consequences, timeline, personal control, treatment control, identity, coherence, emotional representation and concern.

\section{Statistical analysis}

Statistical analysis was performed using the Statistica 10.0 PL software package. The adherence to the therapy of patients diagnosed with asthma or COPD treated with polytherapy with fluticasone propionate and formoterol fumarate using Fantasmino were analyzed according to illness perception as well as age, disease duration and severity.

The opinion of patients on the impact of the use of the Fantasmino inhaler on facilitation adherence and doctors' opinion on facilitation of the patient education, 
Table 1. Study group characteristics

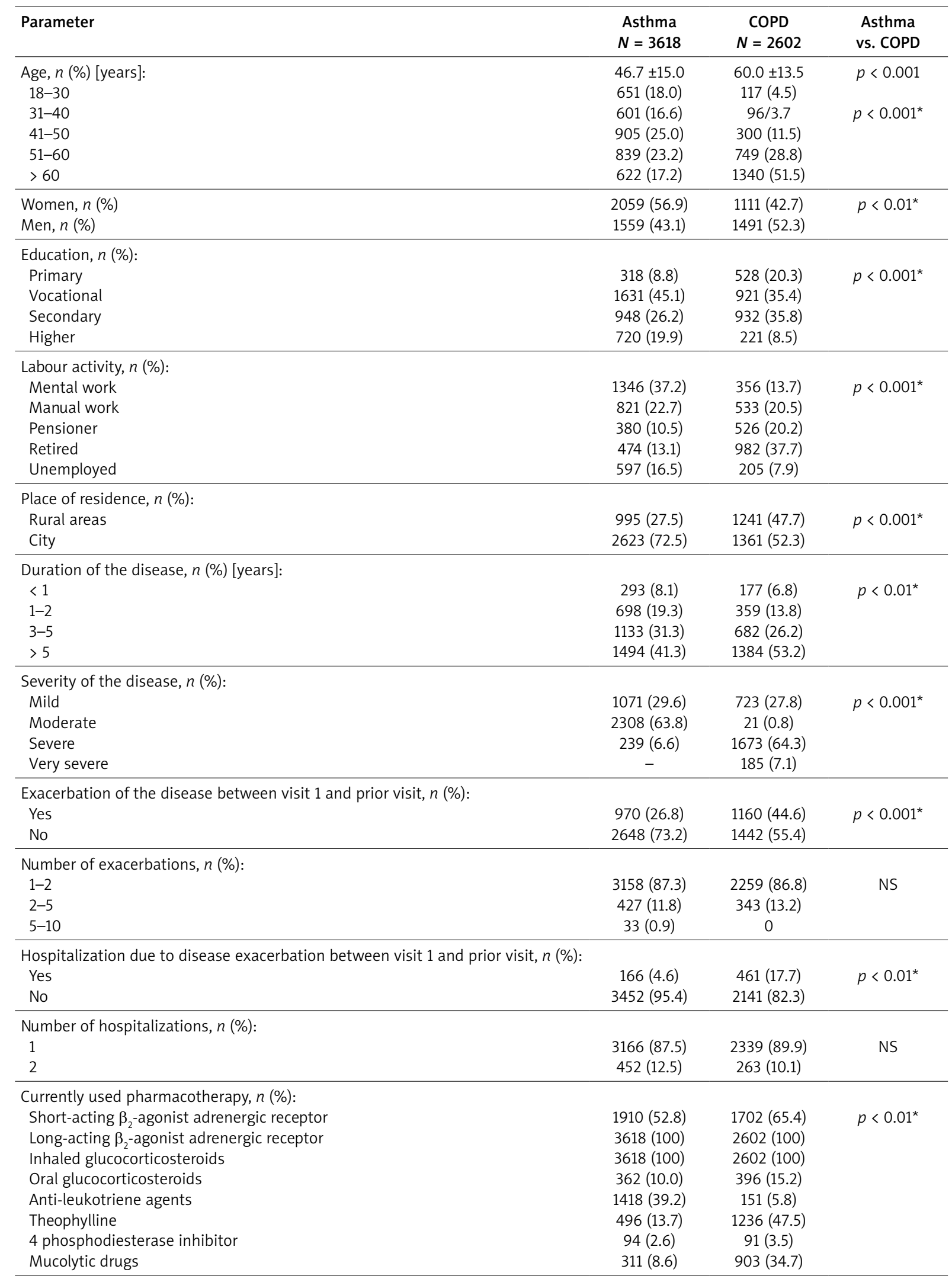


Table 1. Cont.

\begin{tabular}{|c|c|c|c|}
\hline Parameter & $\begin{array}{l}\text { Asthma } \\
N=3618\end{array}$ & $\begin{array}{c}\text { COPD } \\
N=2602\end{array}$ & $\begin{array}{l}\text { Asthma vs. } \\
\text { COPD }\end{array}$ \\
\hline \multicolumn{4}{|c|}{$\begin{array}{l}\text { Duration of use of polytherapy with inhaled glucocorticosteroids and long-acting } \\
\beta_{2} \text {-agonist adrenergic receptor, } n(\%) \text { : }\end{array}$} \\
\hline$<1$ month & $499(13.8)$ & $211(8.1)$ & $p<0.01^{*}$ \\
\hline $1-3$ months & 355 (9.8) & $208(8.0)$ & \\
\hline 3-6 months & 619 (17.1) & $396(15.2)$ & \\
\hline 6-12 months & $311(8.6)$ & 286 (11.0) & \\
\hline$>1$ year & $1834(50.7)$ & $1501(57.7)$ & \\
\hline \multicolumn{4}{|c|}{$\begin{array}{l}\text { Duration of use of inhaled glucocorticosteroids and } \beta_{2} \text {-agonist adrenergic } \\
\text { receptor with the Fantasmino inhaler, } n(\%) \text { : }\end{array}$} \\
\hline$<1$ month & 857 (23.7) & $515(19.8)$ & $p<0.01^{*}$ \\
\hline $1-3$ months & $913(25.2)$ & 484 (18.6) & \\
\hline $3-6$ months & 857 (23.7) & 677 (26.0) & \\
\hline $6-12$ months & 398 (11.0) & 411 (15.8) & \\
\hline$>1$ year & $593(16.4)$ & $515(19.8)$ & \\
\hline
\end{tabular}

${ }^{*} \chi^{2}$ test for trend

reduction in the number of errors made during the inhalation, the treatment effectiveness were also assessed.

Values of variables were presented as percentages and mean values with standard deviations (SD). Separate groups were compared using the $\chi^{2}$ test and $\chi^{2}$ test for trend and $T$ test. The assessment of associations between variables was done with Spearman correlation. A $p<0.05$ was considered as statistically significant.

\section{Results}

\section{Discontinuation of therapy between visit 1 and 2}

Between visit 1 and 2, 16.2\% of patients with asthma and $15.0 \%$ of patients with COPD discontinued therapy with fluticasone propionate and formoterol fumarate using the Fantasmino inhaler. The most common reason for discontinuation in both groups was a conscious decision to stop treatment (22.0\% and $31.9 \%$, respectively). Another reason for discontinuation of therapy was not purchasing the prescription drugs for reasons independent of the patient (13.5\% and $14.9 \%$, respectively). Patients with COPD significantly more frequently than patients with asthma discontinued treatment due to discomfort associated with its use $(24.5 \%$ vs. $11.3 \%, p<0.01)$ and adverse events (13.8\% vs. $7.1 \%, p<0.01)$. In turn, patients with asthma significantly more frequently than with $\mathrm{pa}$ tients with COPD discontinued therapy due to the lack of disease symptoms (14.2\% vs. 5.3\%, $p<0.01)$ and influenced by other people ( $12.1 \%$ vs. $4.3 \%, p<0.001)$ as well as due to disappointment because of no improvement (9.2\% vs. $6.4 \%, p<0.05)$.

\section{Illness perception in asthma and chronic obstructive pulmonary disease groups}

There were no differences in mean score of the illness perception between asthma and COPD groups on visit 1 . However, significantly higher mean scores of the impact of the disease on patient's life, opinion on the duration of disease, assessment of disease severity and the impact of the disease on the emotions were observed in the COPD than in the asthma group. In turn, mean scores of the sense of disease control, opinion that the treatment can help in the disease, understanding the nature of the disease and interest in knowledge about the disease were significantly higher in the asthma than in the COPD group (Table 2).

In both study groups, the mean scores of impact of disease on patient's life, assessment of disease severity and impact of disease on the emotions decreased significantly on visit 2. In turn, the mean score of disease control, and understanding of the disease increased significantly. The mean score of opinion that the treatment can help in the disease and interest in knowledge about the disease increased significantly in the asthma group only. In turn, the mean score of opinion on the duration of disease in the asthma group increased and in the COPD group decreased (Table 2).

\section{Adherence and reasons for non-adherence}

On visit 1, a lower adherence rate was observed in the COPD than in the asthma group (72.0\% vs. $61.5 \%$; $p<0.01)$. During the observation, the adherence rate in the asthma group did not change, while in the COPD group, it increased significantly (61.5\% vs. $73.0 \%$; $p<0.01)$ - Table 3.

In both study groups, the more frequent reason for non-adherence was the organizational causes - haste and forgetfulness; well-being with the lack of conviction about the need for a prescribed drug regimen and the fear of side effects. However, these reasons were significantly more rarely declared by patients diagnosed with COPD than asthma (Table 3).

In the asthma group the non-adherence rate was the highest among subjects aged $18-30$ years $(39.7 \%)$ and 
Table 2. Illness perception

\begin{tabular}{|c|c|c|c|c|}
\hline \multirow[t]{2}{*}{ Parameter } & \multicolumn{2}{|c|}{$\begin{array}{c}\text { Asthma } \\
N=3618\end{array}$} & \multicolumn{2}{|c|}{$\begin{array}{c}\text { COPD } \\
N=2602 \\
\end{array}$} \\
\hline & Visit 1 & Visit 2 & Visit 1 & Visit 2 \\
\hline Total score & $54.3 \pm 9.7$ & $54.0 \pm 9.2$ & $54.3 \pm 10.0$ & $51.9 \pm 10.7^{\# \# \# * * * *}$ \\
\hline $\begin{array}{l}\text { Impact of asthma/COPD on patient's life, } n(\%) \text { : } \\
\text { None at all } \\
\text { Slight } \\
\text { Moderate } \\
\text { Significant } \\
\text { Severe }\end{array}$ & $\begin{array}{c}6.2 \pm 2.5 \\
300(8.3) \\
626(17.3) \\
920(25.4) \\
1077(29.8) \\
695(19.2)\end{array}$ & $\begin{array}{l}5.5 \pm 2.7^{\# \# \#} \\
535(14.8) \\
879(24.3) \\
763(21.1) \\
891(24.6) \\
550(15.2)\end{array}$ & $\begin{array}{c}7.6 \pm 2.2^{\star \star *} \\
49(1.9) \\
208(8.0) \\
467(17.9) \\
840(32.3) \\
1038(39.9)\end{array}$ & $\begin{array}{c}6.7 \pm 2.4^{\# \# \# * \star * *} \\
99(3.8) \\
416(16.0) \\
656(25.2) \\
721(27.7) \\
710(27.3) \\
\end{array}$ \\
\hline $\begin{array}{l}\text { Opinion on the duration of asthma/COPD, } n(\%) \text { : } \\
\text { Very short } \\
\text { Short } \\
\text { Moderately long } \\
\text { Long } \\
\text { Forever }\end{array}$ & $\begin{array}{c}8.4 \pm 1.9 \\
18(0.5) \\
141(3.9) \\
496(13.7) \\
854(23.6) \\
2109(58.3)\end{array}$ & $\begin{array}{c}8.8 \pm 1.8^{\# \# \#} \\
65(1.8) \\
98(2.7) \\
232(6.4) \\
774(21.4) \\
2449(67.7)\end{array}$ & $\begin{array}{c}8.8 \pm 1.7^{\star \star \star} \\
13(0.5) \\
49(1.9) \\
273(10.5) \\
442(17.0) \\
1825(70.1) \\
\end{array}$ & $\begin{array}{c}8.6 \pm 1.9^{\#} \\
10(0.4) \\
143(5.5) \\
274(10.5) \\
432(16.6) \\
1743(67.0) \\
\end{array}$ \\
\hline $\begin{array}{l}\text { Sense of disease control, } n(\%): \\
\text { The total lack } \\
\text { Lack } \\
\text { Partially } \\
\text { Significant } \\
\text { Extreme }\end{array}$ & $\begin{array}{c}6.7 \pm 2.0 \\
58(1.6) \\
506(14.0) \\
988(27.3) \\
1368(37.8) \\
698(19.3) \\
\end{array}$ & $\begin{array}{c}7.4 \pm 1.9^{\# \# \#} \\
47(1.3) \\
283(7.8) \\
698(19.3) \\
1436(39.7) \\
1154(31.9) \\
\end{array}$ & $\begin{array}{c}6.3 \pm 1.9^{\star * *} \\
75(2.9) \\
419(16.1) \\
804(30.9) \\
1026(39.4) \\
278(10.7) \\
\end{array}$ & $\begin{array}{l}6.7 \pm 1.7^{\# \# \# * * *} \\
26(1.0) \\
284(10.9) \\
804(30.9) \\
1132(43.5) \\
356(13.7)\end{array}$ \\
\hline $\begin{array}{l}\text { Opinion on the effects of treatment on asthma/ } \\
\text { COPD, } n(\%): \\
\text { None at all } \\
\text { Slight } \\
\text { Moderate } \\
\text { Significant } \\
\text { Extreme }\end{array}$ & $\begin{array}{c}7.7 \pm 1.7 \\
25(0.7) \\
174(4.8) \\
514(14.2) \\
1650(45.6) \\
1255(34.7)\end{array}$ & $\begin{array}{c}36(1.0) \\
123(3.4) \\
329(9.1) \\
1397(38.6) \\
1733(47.9)\end{array}$ & $\begin{array}{c}7.1 \pm 1.7^{\star * \star} \\
26(1.0) \\
146(5.6) \\
715(27.5) \\
1145(44.0) \\
570(21.9)\end{array}$ & $\begin{array}{l}7.3 \pm 1.8^{\star * *} \\
26(1.0) \\
198(7.6) \\
539(20.7) \\
1103(42.4) \\
736(28.3)\end{array}$ \\
\hline $\begin{array}{l}\text { Assessment of the severity of asthma/COPD } \\
\text { symptoms, } n(\%): \\
\text { No symptoms } \\
\text { Slight } \\
\text { Moderate } \\
\text { Significant } \\
\text { Many severe symptoms }\end{array}$ & $\begin{array}{c}369(10.2) \\
734(20.3) \\
1111(30.7) \\
1111(30.7) \\
293(8.1)\end{array}$ & $\begin{array}{c}897(24.8) \\
1071(29.6) \\
865(23.9) \\
601(16.6) \\
184(5.1) \\
\end{array}$ & $\begin{array}{c}6.7 \pm 1.9^{\star \star \star} \\
65(2.5) \\
242(9.3) \\
757(29.1) \\
1129(43.4) \\
409(15.7) \\
\end{array}$ & $\begin{array}{c}5.5 \pm 2.1^{\# \# \# \star * \star} \\
190(7.3) \\
682(26.2) \\
853(32.8) \\
677(26.0) \\
200(7.7) \\
\end{array}$ \\
\hline $\begin{array}{l}\text { Interest in knowledge about the disease, } n(\%) \text { : } \\
\text { None at all } \\
\text { Slight } \\
\text { Moderate } \\
\text { Great } \\
\text { Extreme }\end{array}$ & $\begin{array}{c}7.8 \pm 2.1 \\
62(1.7) \\
188(5.2) \\
771(21.3) \\
933(25.8) \\
1664(46.0) \\
\end{array}$ & $\begin{array}{c}8.0 \pm 2.0^{\#} \\
40(1.1) \\
184(5.1) \\
579(16.0) \\
962(26.6) \\
1853(51.2)\end{array}$ & $\begin{array}{l}6.7 \pm 2.4^{\star \star *} \\
146(5.6) \\
333(12.8) \\
713(27.4) \\
744(28.6) \\
666(25.6)\end{array}$ & $\begin{array}{l}6.6 \pm 2.5^{\star * *} \\
148(5.7) \\
422(16.2) \\
682(26.2) \\
619(23.8) \\
731(28.1)\end{array}$ \\
\hline $\begin{array}{l}\text { Understanding the nature of the disease, } n(\%) \text { : } \\
\text { None at all } \\
\text { A little } \\
\text { Moderate } \\
\text { Good } \\
\text { Very good }\end{array}$ & $\begin{array}{c}6.5 \pm 2.2 \\
145(4.0) \\
499(13.8) \\
1158(32.0) \\
1035(28.6) \\
781(21.6)\end{array}$ & $\begin{array}{l}7.1 \pm 2.1^{\# \# \#} \\
90(2.5) \\
318(8.8) \\
919(25.4) \\
1274(35.2) \\
1017(28.1)\end{array}$ & $\begin{array}{c}5.4 \pm 2.2^{* * *} \\
291(11.2) \\
508(19.5) \\
1054(40.5) \\
549(21.1) \\
200(7.7)\end{array}$ & $\begin{array}{l}5.7 \pm 2.2^{\# \star * *} \\
250(9.6) \\
468(18.0) \\
856(32.9) \\
763(29.3) \\
265(10.2)\end{array}$ \\
\hline $\begin{array}{l}\text { The impact of asthma/COPD on the emotions, } n(\%) \text { : } \\
\text { Lack } \\
\text { Slight } \\
\text { Moderate } \\
\text { Significant } \\
\text { Extreme }\end{array}$ & $\begin{array}{c}5.4 \pm 2.4 \\
535(14.8) \\
768(21.2) \\
1020(28.2) \\
861(23.8) \\
434(12.0)\end{array}$ & $\begin{array}{l}4.8 \pm 2.6^{\# \# \#} \\
952(26.3) \\
800(22.1) \\
763(21.1) \\
810(22.4) \\
293(8.1)\end{array}$ & $\begin{array}{l}5.7 \pm 2.3^{*} \\
265(10.2) \\
505(19.4) \\
864(33.2) \\
684(26.3) \\
284(10.9)\end{array}$ & $\begin{array}{l}5.1 \pm 2.3^{\# \# \star} \\
458(17.6) \\
619(23.8) \\
729(28.0) \\
635(24.4) \\
161(6.2)\end{array}$ \\
\hline
\end{tabular}

${ }^{*} p<0.05 ;{ }^{* * *} p<0.001$ asthma vs. COPD, ${ }^{\#} p<0.05 ; "{ }^{\# \# *} p<0.001$ visit 1 vs. visit 2 
Table 3. Adherence during the observation period and factors influencing non-adherence

\begin{tabular}{|c|c|c|c|c|}
\hline \multirow[t]{2}{*}{ Parameter } & \multicolumn{2}{|c|}{ Asthma $N=3618$} & \multicolumn{2}{|c|}{ COPD $N=2602$} \\
\hline & Visit 1 & Visit 2 & Visit 1 & Visit 2 \\
\hline \multicolumn{5}{|l|}{ Results of Morisky questionnaire, $n(\%)$ : } \\
\hline Adherence ( $\leq 4$ points) & $2605(72.0)$ & $2551(70.5)$ & $1600(61.5)^{\wedge \wedge \star \star}$ & 1899 (73.0) \\
\hline Non-adherence (> 4 points) & $1013(28.0)$ & $1067(29.5)$ & $1002(38.5)$ & $703(27.0)$ \\
\hline \multicolumn{5}{|l|}{ Reasons for non-adherence [\%]: } \\
\hline Organizational causes - haste, forgetfulness & $2012(55.6)$ & $806(22.3)^{\star \star \star}$ & $965(37.1)^{\wedge \wedge \wedge}$ & $492(18.9)^{\wedge \wedge \wedge}$ \\
\hline $\begin{array}{l}\text { Well-being - the lack of conviction about the need for } \\
\text { a prescribed drug regimen }\end{array}$ & $1324(36.6)$ & $637(17.6)^{\star \star *}$ & $565(21.7)^{\wedge \wedge \wedge}$ & $263(10.1)^{\star * \star \wedge \wedge}$ \\
\hline Fear of side effects & $802(22.2)$ & $340(9.4)^{\star * *}$ & $346(13.3)^{\wedge \wedge \wedge}$ & $94(3.6)^{\star * \star \wedge \wedge \wedge}$ \\
\hline Desire to reduce the number of drugs used daily & $626(17.3)$ & $83(2.3)^{\star * \star}$ & $606(23.3)^{\wedge \wedge}$ & $138(5.3)^{\star \star \star \wedge \wedge}$ \\
\hline Difficulties in the use of the inhaler & $90(2.5)$ & 0 & $206(7.9)$ & 0 \\
\hline A conscious decision not to purchase a prescribed drug & $90(2.5)$ & 0 & $86(3.3)$ & $31(1.2)$ \\
\hline $\begin{array}{l}\text { Non-purchase of prescribed drugs for reasons beyond } \\
\text { the patient }\end{array}$ & $119(3.3)$ & $28(0.8)$ & $140(5.4)$ & 0 \\
\hline Poor understanding of instructions from the doctor & $119(3.3)$ & 0 & $109(4.2)$ & $31(1.2)$ \\
\hline The method of taking the drug is complicated & $14(0.4)$ & 0 & $55(2.1)$ & 0 \\
\hline Disappointment with the lack of improvement & $192(5.3)$ & $65(1.8)$ & $229(8.8)$ & 0 \\
\hline $\begin{array}{l}\text { The high cost of treatment (less frequent use of the } \\
\text { drug will bring savings) }\end{array}$ & $90(2.5)$ & $14(0.4)$ & $140(5.4)$ & 0 \\
\hline $\begin{array}{l}\text { Frequent trips and forgetting to take the drug with the } \\
\text { patient }\end{array}$ & $253(7.0)$ & $72(2.0)$ & $86(3.3)$ & $31(1.2)$ \\
\hline Shift work system & $329(9.1)$ & $58(1.6)$ & $185(7.1)$ & $47(1.8)$ \\
\hline $\begin{array}{l}\text { Lack of medicine, long waiting time for a visit to get } \\
\text { a prescription }\end{array}$ & $148(4.1)$ & $83(2.3)$ & $130(5.0)$ & 0 \\
\hline Other & 0 & 0 & $21(0.8)$ & 0 \\
\hline
\end{tabular}

${ }^{* \star} p<0.01 ;{ }^{* * *} p<0.001$ visit 1 vs. visit $2 ; \wedge \wedge p<0.01 ; \wedge \wedge \wedge p<0.001$ asthma vs. COPD

the lowest among subjects aged over 60 years (15.4\%). In the COPD group, the non-adherence rate was the highest among subjects aged $31-40$ years (56.5\%) and the lowest among subjects aged $41-50$ years (31.9\%). Difficulties with the inhaler use as the cause of non-adherence in both study groups were most frequently reported by patients aged over 60 years (5.4\% and $4.7 \%$, respectively) - data not shown.

In the asthma group the non-adherence rate was the highest among subjects with disease duration over 5 years (43.9\%) and in the COPD group, among subjects with disease duration of less than 1 year (43.5\%). However, difficulties with the inhaler use as the cause of non-adherence in the asthma group were most frequently reported by subjects with disease duration of less than 5 years and in the COPD group by subjects with disease duration over 5 years (2.9\% and $4.9 \%$, respectively) data not shown.

In the asthma group, the non-adherence rate was the lowest among patients with mild disease severity and in the COPD group among patients with very severe disease (16.6\% and $35.3 \%$, respectively). Difficulties with the inhaler use as the cause of non-adherence in the asthma group were most frequently reported by subjects with moderate disease severity and in the COPD group by subjects with mild disease severity $(5.0 \%$ and $3.2 \%$, respectively) - data not shown.

\section{Adherence and illness perception}

On visit 1, the mean total score of illness perception in both study groups was significantly higher in adherence than non-adherence subgroups, while, on visit 2, this difference was observed in the asthma group only (Table 4).

There were no differences in mean score of the impact of the disease on patient's life between adherence and non-adherence asthma subgroups on visit 1 and on visit 2, the impact was significantly higher in non-adherence than adherence subgroups. In turn, in the COPD group on both visits the impact of the disease did not differ between adherence and non-adherence subgroups (Table 4).

The mean score of the opinion on the duration of the disease on visit 1 was significantly higher in adherence than non-adherence subgroups in both asthma and COPD groups, while, on visit 2 , this difference was observed in the COPD group only (Table 4).

The mean score of sense of disease control was significantly higher in adherence than non-adherence subgroup on both visits and in both study groups (Table 4).

The mean score of opinion on the effect of treatment on both visits in both study groups was significantly higher in the adherence than non-adherence subgroup (Table 4). 


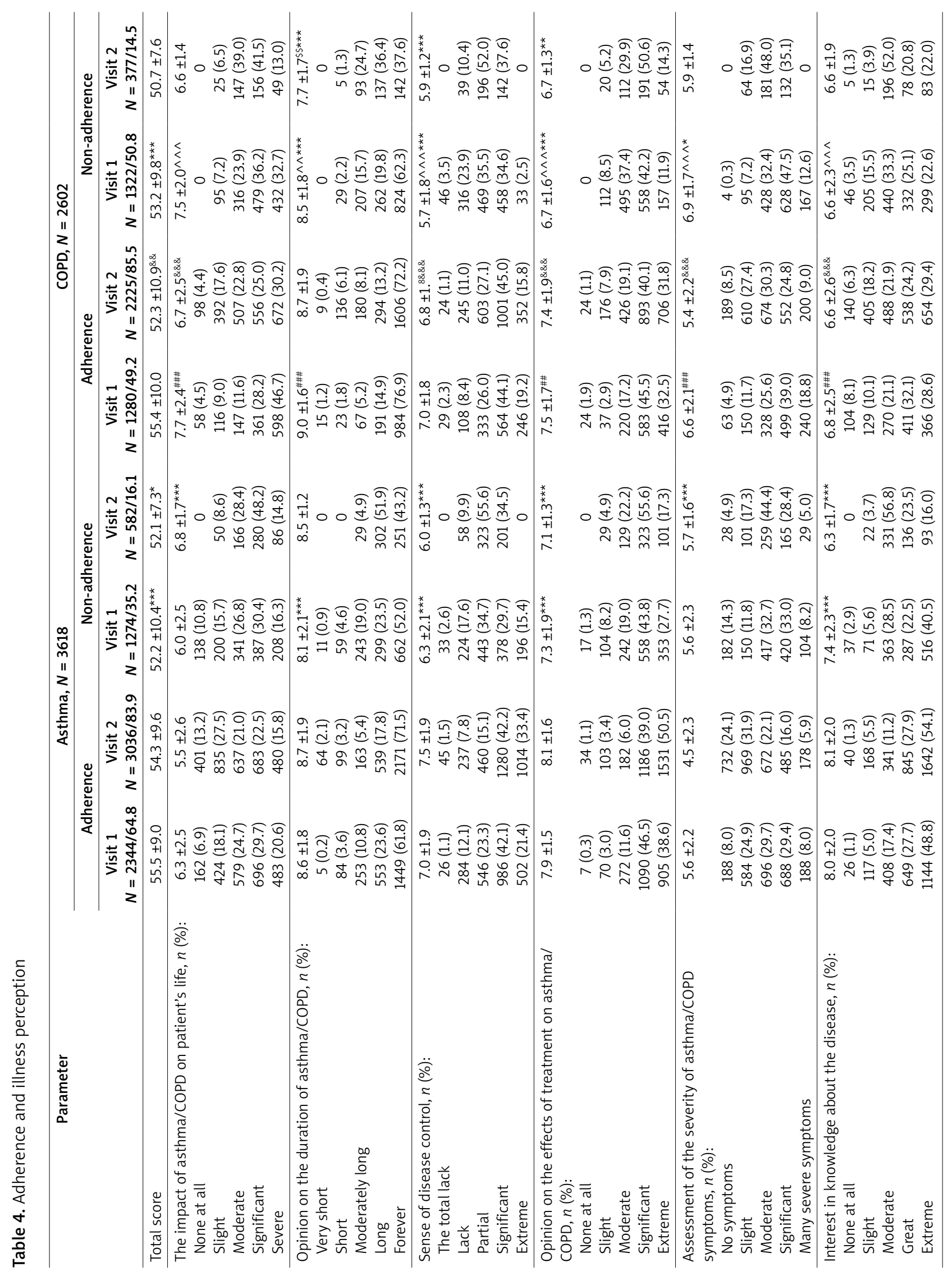




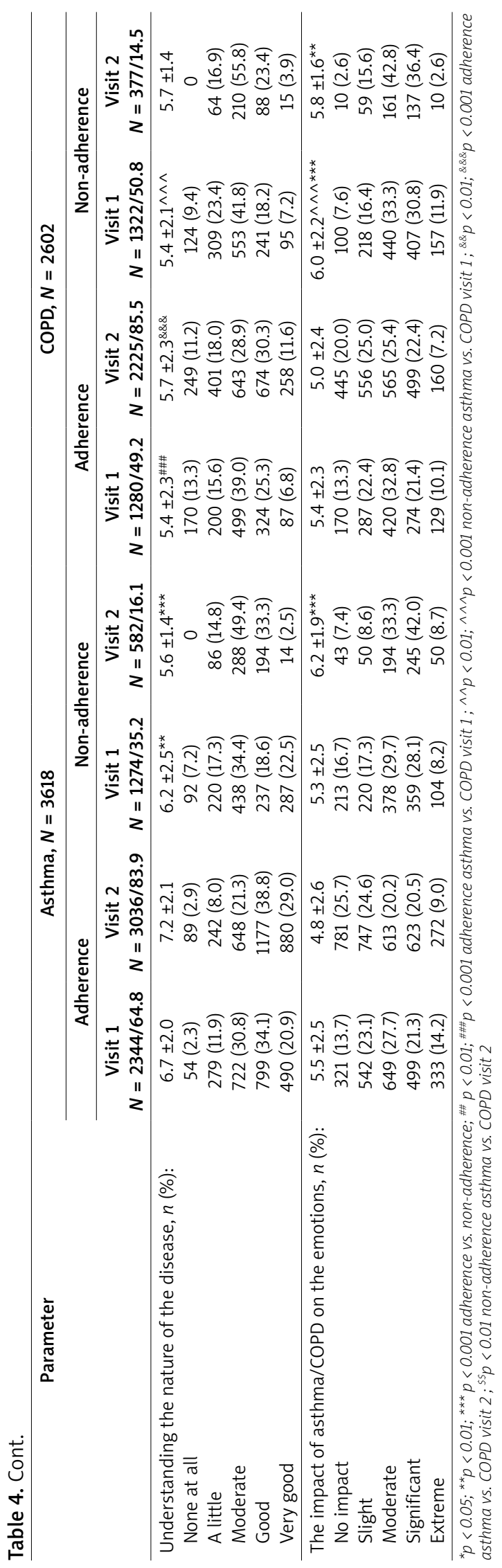

The mean score of patient assessment of the severity of the disease on visit 1 did not differ between asthma adherence and non-adherence subgroups and on visit 2 was significantly higher in the non-adherence than adherence subgroup. In turn, in the COPD group, on visit 1, it was significantly higher in the non-adherence than adherence subgroup and on visit 2, it did not differ (Table 4).

On both visits, the mean score of the understanding of the nature and interest in knowledge about the disease was significantly higher in asthma adherence than non-adherence subgroup and did not differ between COPD subgroups (Table 4).

On both visits, the mean score of the impact of the disease on the emotions was significantly higher in COPD non-adherence than adherence subgroup and on visit 2, it was also higher in asthma non-adherence than adherence subgroups (Table 4).

A significant negative correlation between total MMAS-8 and BIPQ scores was observed in both asthma and COPD groups $(R=-0.15 ; p<0.001$ and $R=-0.24$; $p<0.001$, respectively).

In the asthma group, a significant negative correlation has been observed between total MMAS- 8 score and the score of BIPQ such as sense of disease control, opinion on the effect of treatment on the disease, understanding the nature of the disease and interest in knowledge about the disease $(R=-0.30 ; p<0.001$, $R=-0.23 ; p<0.0001, R=-0.32 ; p<0.0001$ and $R=-0.15 ; p<0.001$, respectively).

In the COPD group, a significant negative correlation has also been shown between total MMAS-8 score and the score of BIPQ such as opinion on the duration of disease, sense of disease control and opinion on the effect of treatment on the disease $(R=-0.20 ; p<0.001$, $R=-0.39 ; p<0.0001$ and $R=-0.33 ; p<0.001$, respectively).

\section{Patients' and doctors' opinion about the use of two drugs in a single inhaler}

During the observation, the percentage of patients who believed that the administration of the two drugs in a single inhaler considerably facilitates their use increased significantly in both asthma and COPD groups (Table 5).

There have also been significant changes in the opinions of doctors. On visit 1, all doctors believed that the possibility of administration of the two drugs in a single inhaler does not facilitate education of patients diagnosed with asthma and COPD at all, while on visit 2, $82.0 \%$ of doctors believed that this option significantly facilitates education of patients diagnosed with asthma and $75.2 \%$ that patients with COPD. During the observation, there was also a significant increase in the percentage of doctors expressing an opinion that administration of the two drugs in a single inhaler significantly decreased the number of errors made by the patients with asthma and COPD. However, the percentage of doc- 


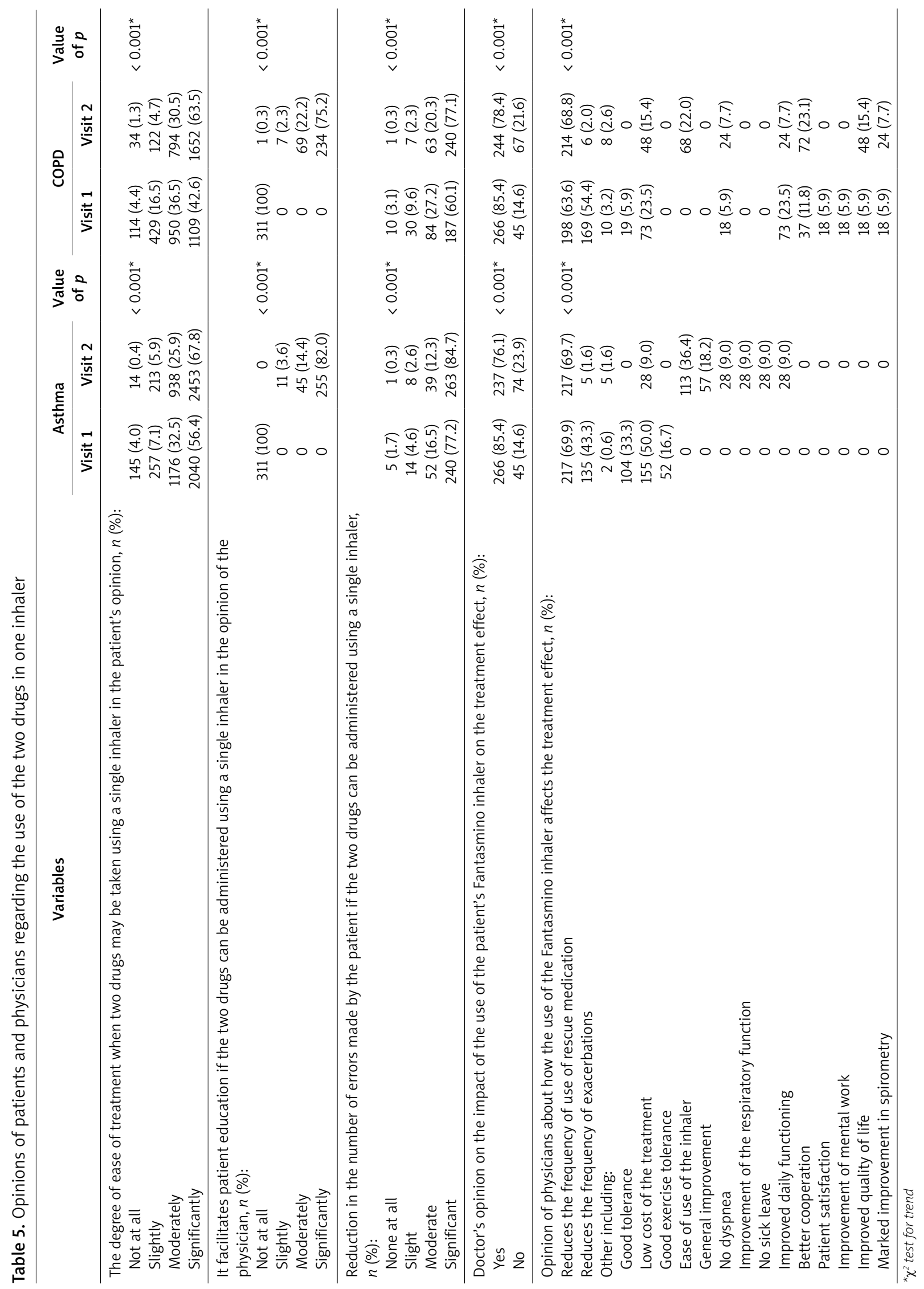


tors who believe that the use of the Fantasmino inhaler has an impact on the treatment effect in patients with asthma and COPD decreased significantly. The opinions of doctors about how the use of the Fantasmino inhaler affects the treatment effect are shown in Table 5.

\section{Discussion}

The presented study is the first large survey performed in the Polish population. The analysis of study group characteristics has shown that its structure is representative of Polish patients with asthma [11, 12]. However, the group of patients with COPD does not seem to be representative of the Polish population, due to greater than expected participation of women and rural residents. It is in contrast with previously published studies showing that men develop COPD almost twice as often as women [13] and that COPD is more common among urban dwellers [14, 15]. However, it should be noted that these studies were performed more than a decade ago and COPD's major risk factors such as smoking and environmental pollution have changed in the meantime. Thus, it cannot be excluded that the group of patients with COPD is now representative of the Polish population.

In both study groups, most patients had a diagnosis of the disease for more than 5 years prior to enrollment. However, the study groups differ in terms of disease severity. In the asthma group, only $6.6 \%$ of patients have severe disease and in the COPD group, $64.3 \%$ of patients have severe and $7.1 \%$ very severe disease. $50.7 \%$ of the asthma group and $57.7 \%$ of the COPD group were treated with fluticasone propionate and formoterol fumarate for more than a year. However, this therapy using the Fantasmino inhaler for more than a year was conducted only in $16.4 \%$ and $19.8 \%$, respectively, and for not more than 3 months in $48.8 \%$ and $38.4 \%$, respectively. A recently published review showed that this type of therapy in patients with asthma is effective in terms of the lung function and symptom control and highlights the dose flexibility, safety and tolerability of this new inhaled combination [16]. In addition, the TORCH study revealed that this therapy decreased the number of exacerbations and improved the health status as well as spirometry measurements. In addition, it also reduced the risk of death in patients with COPD by $17.5 \%$ [17].

The general illness perception was similar in both study groups. However, significantly higher mean scores of the impact of the disease on the patient's life, opinion on the duration of disease, assessment of disease severity and the impact of the disease on the emotions were observed in COPD than in the asthma group. In turn, mean scores of the sense of disease control, opinion that the treatment can help in the disease, understanding the nature of the disease and interest in knowledge about the disease were significantly higher in asthma than in the COPD group. It should be emphasized that during ob- servation there have been positive changes in the illness perception in both study groups. The results of a recently published study showed that health-related quality of life (HRQoL) of COPD patients is associated with illness perception as well as with the severity of dyspnea as experienced by patients. It has also been suggested that interventions focusing on illness perception helped to support COPD patients in their disease management and to improve HRQoL [18]. The present study did not assess the education process during observation but the positive changes in illness perception suggest than greater focus of the doctor on the patient in connection with his participation in the study has a positive effect on the process.

The non-adherence rate on visit 1 was lower in asthma than in the COPD group. It should be noted that adherence in the asthma group (72.0\%) was higher than reported in recently published meta-analysis (from $22.0 \%$ to 63\%) [19]. As suggested, the results of this meta-analysis may be a result of polytherapy with inhaled glucocorticosteroids and long-acting $\beta_{2}$ agonists used in the present study. In turn, the adherence in the COPD group (61.5\%) was similar to that previously reported [7]. However, it should be emphasized that during observation the adherence increased significantly in the COPD group only. This may be the effect of changes in the illness perception. Positive changes have also been observed in the asthma group though. On the other hand, impact of disease duration and its severity may be factors partially explaining these differences. Further studies are necessary to explain the differences in the impact of illness perception on adherence between patients with asthma and COPD.

On visit 1 , the mean total score of illness perception in both study groups was significantly higher in adherence than non-adherence subgroups. In turn, on visit 2 , this difference was observed in the asthma group only. In addition, a negative correlation between total MMAS-8 and BIPQ scores was observed in both asthma and COPD groups. Moreover, in both asthma and COPD groups non-adherence was inversely proportional to the sense of disease control and opinion on the effect of treatment on the disease. The association between belief that treatment is ineffective in controlling symptoms and poor adherence has also been described previously among patients with asthma and COPD [20-22]. In turn, the association between sense of disease control has not been previously observed. It should be also noted that this association requires confirmation in studies with other questionnaires assessing sense of disease control. The present study has also shown that adherence was inversely proportional to understanding the nature of the disease and interest in knowledge about the disease. This study did not assess the levels of knowledge about disease. In turn, in the GAPP study, $23.0 \%$ of patients thought that education is not conducted at all [23]. Thus, further studies should be performed to assess the association between education levels about disease and adherence. 
The additional assessment in this study was opinions of patients and doctors on the Fantasmino inhaler use. During the observation, the percentage of patients who believed that the administration of the two drugs in a single inhaler considerably facilitates their use increased significantly in both asthma and COPD groups. There have also been significant changes in the opinions of doctors. On visit 1, all doctors, contrary to a previously published study [24], believed that the possibility of administration of the two drugs in a single inhaler does not facilitate education of patients diagnosed with asthma and COPD at all. In turn, on visit 2, $82.0 \%$ of doctors believed that this option significantly facilitates education of patients diagnosed with asthma and $75.2 \%$ that it facilitates education of patients with COPD. In accordance to previously published studies $[10,24]$ during observation, there was a significant increase in the percentage of doctors expressing an opinion that administration of the two drugs in a single inhaler significantly decreased the number of errors made by the patients with asthma and COPD.

The study has several limitations. The most important is the lack of a control group treated with fluticasone propionate and formoterol fumarate without using the Fantasmino inhaler. The second limitation is the self-reported assessment of adherence. The factors influencing the results may be also the patient's education during observation and the level of knowledge about disease before enrollment. In addition, the differences in duration of disease and therapy with the Fantasmino inhaler may influence the results of this study. Moreover, in this study the impact of comorbidities and use of other drugs on the illness perception and adherence was not analyzed.

However, the strength of the study is a large study group representative of the Polish population and multicenter nature of the study.

\section{Conclusions}

The illness perception, younger age, disease duration and severity are predictors of adherence to treatment with fluticasone propionate and formoterol fumarate using the Fantasmino inhaler among patients with asthma and COPD. The positive opinions of patients and doctors about administration of fluticasone propionate and formoterol fumarate using the Fantasmino inhaler increased during observation.

\section{References}

1. Smoliński B, Sybilski AJ, Raciborski F, et al. Prevalence of asthma in children, adolescents and young adults in Poland - results of the ECAP study [Polish]. Alergia Astma Immunologia 2009; 14: 27-34.

2. Bednarek M, Maciejewski J, Woźniak M, et al. Prevalence, severity and underdiagnosis of COPD in the primary care setting. Thorax 2008; 63: 402-7.

3. Global Strategy for the Diagnosis, Management and Prevention of COPD, Global Initiative for Chronic Obstructive
Lung Disease (GOLD). Updated 2013. Available from: http:// www.goldcopd.org/.

4. Global Strategy for Asthma Management and Prevention (GINA). Revised 2014. Available from: http://www.ginasthma.com/

5. Clark NM, Cabana MD, Nan B, et al. The clinician-patient partnership paradigm: outcomes associated with physician communication behavior. Clin Pediatr (Phila) 2008; 47: 49-57.

6. Bender BG, Pedan A, Varasteh LT. Adherence and persistence with fluticasone propionate/salmeterol combination therapy. J Allergy Clin Immunol 2006; 118: 899-904.

7. Bryant J, McDonald VM, Boyes A, Sanson-Fisher R, Paul C, Melville J. Improving medication adherence in chronic obstructive pulmonary disease: a systematic review. Respir Res 2013; 14: 109.

8. Restrepo RD, Alvarez MT, Wittnebel LD, et al. Medication adherence issues in patients treated for COPD. Int J Chron Obstruct Pulmon Dis 2008; 3: 371-84.

9. Hesselink AE, Penninx BW, Wijnhoven HA, et al. Determinants of an incorrect inhalation technique in patients with asthma or COPD. Scand J Prim Health Care 2001; 19: 255-60.

10. Van der Palen J, Klein JJ, van Herwaarden CLA, et al. Multiple inhalers confuse asthma patients. Eur Respir J 1999; 14: 1034-7.

11. Małolepszy J, Liebhart J, Wojtyniak B, Pisiewicz K, Płusa T. Występowanie chorób alergicznych w Polsce [Polish]. Alergia Astma Immunologia VII Zjazd PTA Łódź 2000; S2: 163-9.

12. Liebhart J, Małolepszy J, Wojtyniak B, et al. Prevalence and Risk Factors for Asthma in Poland: results From the PMSEAD Study. I Investig Allergol Clin Immunol 2007; 6: 367-74.

13. Krzyżanowski M, Jędrychowski W, Wysocki M. Factors associated with the change in ventilatory function and the development of chronic obstructive pulmonary disease in a 13-year follow-up of the Cracow Study. Risk of chronic obstructive pulmonary disease. Am Rev Respir Dis 1986; 134: 1011-9.

14. Plywaczewski R, Bednarek M, Jonczak L, Zielinski J. Prevalence of COPD in Warsaw population. Pneumonol Alergol Pol 2003; 71: 329-35.

15. Niepsuj G, Kozielski J, Niepsuj K, et al. Chronic obstructive pulmonary disease in inhabitants of Zabrze. Wiad Lek 2002; 55: 354-9.

16. Papi A, Blasi F, Canonica GW, et al. Fluticasone propionate/ formoterol: A fixed-combination therapy with flexible dosage. Eur J Intern Med 2014 Jul 19. pii: S0953-6205(14)00194-0. doi: 10.1016/j.ejim.2014.06.022. [Epub ahead of print].

17. Calverly P, Anderson J, Celli B, et al. Salmeterol and fluticasone propionate and survival in chronic obstructive pulmonary disease. N Engl J Med 2007; 356: 775-89.

18. Weldam SW, Lammers JW, Heijmans MJ, Schuurmans MJ. Perceived quality of life in chronic obstructive pulmonary disease patients: a cross-sectional study in primary care on the role of illness perceptions. BMC Fam Pract 2014; 15: 140.

19. Barrnes CB, Ulrik CS. Asthma and adherence to inhaled corticosteroids: current status and future perspectives. Respir Care 2014 Aug 12. pii: respcare.03200 [Epub ahead of print].

20. Charles C, Ninot G, Sultan S. Patients' illness perceptions and adherence to treatment with inhaled corticosteroids in asthma. Rev Mal Respir 2011; 28: 626-35.

21. Sofianou A, Martynenko M, Wolf MS, et al. Asthma beliefs are associated with medication adherence in older asthmatics. J Gen Intern Med 2013; 28: 67-73.

22. Krauskopf K, Federman AD, Kale MS, et al. Chronic obstructive pulmonary disease illness and medication beliefs are 
associated with medication adherence. COPD 2014 Jun 24 [Epub ahead of print].

23. Canonica GW, Baena-Cagnani CE, Blaiss MS, Dahl R, Kaliner MA, Valovirta EJ; GAPP Survey Working Group. Unmet needs in asthma: Global Asthma Physician and Patient (GAPP) Survey: global adult findings. Allergy 2007; 62: 668-74.

24. Hesselink AE, Penninx BW, Wijnhoven HA, et al. Determinants of an incorrect inhalation technique in patients with asthma or COPD. Scand J Prim Health Care 2001; 19: 255-60. 